\title{
Transfer bond stresses generated between FRP tendons and concrete
}

\author{
J. M. Lees* and C. J. Burgoyne* \\ University of Cambridge
}

There is a growing interest in the use of new materials in construction. Materials such as fibre-reinforced plastics (FRPs) are lightweight, strong, and, for the most part, non-corrodible. Hence, the use of FRPs as prestressing tendons for concrete represents a viable, durable alternative to conventional practice using prestressing steel. This paper addresses the nature of the bond between an FRP tendon and concrete in the transfer zone of a pretensioned concrete beam. In particular, two different types of aramid fibre-reinforced plastics (AFRPs) are considered. In the experimental investigation, the tendon pull-in behaviour during detensioning of a number of small-scale $(100 \times 200 \times 2800 \mathrm{~mm})$ pretensioned concrete beams was monitored. These results were then used to make inferences about the bond stress distribution through the transfer zone. Both a constant and a non-linear relationship between the bond shear stress and the tendon slip were considered and the transfer behaviour of the two types of AFRP and steel were compared. It was found that by assuming a non-uniform bond stress distribution some interesting results about the distinctly different natures of the bond behaviour of the three materials were obtained.

\section{Notation}

$A_{\mathrm{c}} \quad$ area of concrete

$A_{\mathrm{t}} \quad$ area of tendon

$b_{1}, b_{2}, b_{3}$ constants

$b_{3 \text { adj }} \quad$ coefficient $b_{3}$ modified to account for variations in concrete strength

C constant

$D_{1}, D_{2} \quad$ constants

$E_{\mathrm{c}} \quad$ modulus of elasticity of concrete

$E_{\mathrm{t}} \quad$ modulus of elasticity of tendon

$F \quad$ tendon force transferred to the concrete

$f_{\mathrm{cu}} \quad$ concrete compressive cube strength

$K \quad$ constant

$L_{\mathrm{t}} \quad$ transfer length

$m \quad$ modular ratio $\left(m=E_{\mathrm{t}} / E_{\mathrm{c}}\right)$

$N \quad$ constant which reflects shape of bond stress-slip distribution

$P_{\mathrm{d}} \quad$ tendon force at free end of beam

$P_{0} \quad$ initial prestress force

$P_{\text {ult }} \quad$ manufacturer's assured load for tendon

$s_{\mathrm{d}} \quad$ tendon draw-in at free end of beam

\footnotetext{
* Department of Engineering, University of Cambridge, Trumpington Street, Cambridge CB2 1PZ, UK

(MCR 707) Paper received 26 May 1998; last revised 17 December 1998; accepted 18 February 1998
}

$\begin{array}{ll}s_{x} & \text { slip at point } x \\ T & \text { force in tendon } \\ V_{\mathrm{f}} & \text { volume fraction of fibres } \\ x & \text { distance from point at which } \\ & s_{x}=\mathrm{d} s_{x} / \mathrm{d} x=0 \\ \rho & \text { ratio of tendon area to concrete area } \\ & \left(\rho=A_{\mathrm{t}} / A_{\mathrm{c}}\right) \\ \tau & \text { bond shear stress } \\ \tau_{\mathrm{t}} & \text { transfer bond stress } \\ \phi & \text { bar diameter }\end{array}$

\section{Introduction}

The term fibre-reinforced plastic (FRP) describes a group of materials which are made up of continuous organic or inorganic fibres in a resin matrix. The material properties of FRPs are fundamentally different from those of steel and, in particular, FRPs are linearly elastic and do not yield. It is therefore important to develop a design basis for these materials which reflects an understanding of the strengths and weaknesses of these novel materials.

In the current work the bond behaviour of two types of aramid FRP (AFRP), FiBRA and Technora, were considered (Table 1). FiBRA ${ }^{1}$ is a composite rod made up of aramid fibres (Kevlar 49) in an epoxy resin 
Table 1. Tendon and fibre material properties ${ }^{2-6}$

\begin{tabular}{|c|c|c|c|c|c|c|}
\hline Material & Density: $\mathrm{kg} / \mathrm{m}^{3}$ & Fibre type & $\begin{array}{l}\text { Young's modulus: } \\
\text { GPa }\end{array}$ & $\begin{array}{c}\text { Max. elongation: } \\
\%\end{array}$ & $\begin{array}{c}\text { Tensile strength: } \\
\mathrm{MPa}\end{array}$ & $V_{\mathrm{f}}: \%$ \\
\hline $\begin{array}{l}\text { FiBRA } \\
\text { Kevlar } 49 \text { fibre } \\
\text { Technora rod } \\
\text { Technora fibre } \\
\text { Steel (high yield) } \\
\text { Steel (prestress) }\end{array}$ & $\begin{array}{l}1 \cdot 28 \\
1 \cdot 45 \\
1 \cdot 3 \\
1 \cdot 39 \\
7 \cdot 8 \\
7 \cdot 8\end{array}$ & $\begin{array}{c}\text { Kevlar } 49 \\
\text { NA } \\
\text { Technora } \\
\text { NA } \\
\text { NA } \\
\text { NA }\end{array}$ & $\begin{array}{r}68 \cdot 6 \\
120 \cdot 0 \\
54 \cdot 0 \\
73 \cdot 0 \\
200 \\
220\end{array}$ & $\begin{array}{c}2.0 \\
2 \cdot 5 \\
3 \cdot 7 \\
4 \cdot 6 \\
10 \cdot 0 \\
4.2^{*}\end{array}$ & $\begin{array}{r}1480 \\
2800 \\
1900 \\
3400 \\
650 \\
1760\end{array}$ & $\begin{array}{c}65-70 \\
\mathrm{n} / \mathrm{a} \\
65 \\
\mathrm{n} / \mathrm{a} \\
\mathrm{n} / \mathrm{a} \\
\mathrm{n} / \mathrm{a}\end{array}$ \\
\hline
\end{tabular}

* Measured value.

matrix. In the manufacturing process, the continuous fibres are braided before being impregnated with resin (Fig. 1). The suggested advantages of braiding are a uniform transmission of tensile force through the crosssection and an improved bond. The disadvantages include increased manufacturing complexity and a possible reduction in strength because of local contact stresses.

Technora rod is made up of bundles of aramid fibres impregnated with vinylester resin. ${ }^{7}$ After the Technora fibres are pulled through the resin die, a winding fibre is wound around the rod to deform its surface. The winding fibre is held in place by a longitudinal securing fibre and a helical securing fibre, both of which are fixed with resin (Fig. 1). The surface texture ensures a good bond with concrete.

The surface profile and properties of an FRP rod will affect the bond behaviour and, in the current work, the differences in the transfer bond behaviour of the two types of AFRP rods are highlighted and compared with that of steel. In particular, the transfer zone of smallscale $(100 \times 200 \times 2800 \mathrm{~mm})$ pretensioned concrete beams is studied. This work was carried out in conjunction with an investigation of the influence of bond on the flexural rotation capacity of concrete beams with AFRP prestressing tendons, details of which can be found elsewhere. ${ }^{8}$

\section{Bond behaviour}

\section{Bond mechanisms}

Bond forces are typically transferred from a tendon to concrete through a combination of three mechan-
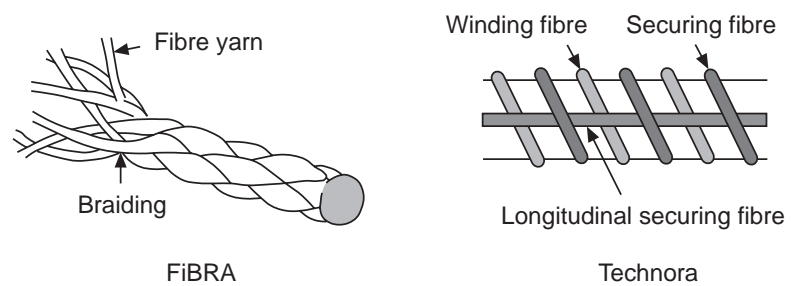

Fig. 1. FiBRA and Technora rod r.7 $^{2,7}$ isms: mechanical interlock, chemical adhesion and friction.

Mechanical interlock. The surface profile of a rod will dictate the amount of mechanical bond that can be generated between the rod and the concrete. The mechanical bond of deformed steel reinforcement bars is typically enhanced during the manufacture by creating a series of ribs along the length of the bar. In contrast, steel prestress wire tends to have a smooth surface and there is limited mechanical bond between the wire and the concrete.

FRP manufacturers have tried to improve the mechanical bond of their products by creating rods with deformed surface profiles and/or by coating the rods with sand. Numerous different profiles have been produced and surface deformations have been formed either in the outer layer of the resin or with the fibres themselves.

One of the big problems with the diversity and number of available FRP profiles is that the mechanical bond characteristics of each type of rod will be different. It is generally accepted that the industry must look to standardize FRP products in order to encourage the use of new materials but, as yet, no unique set of desirable characteristics has been identified.

For deformed steel bars, mechanical interlock is thought to be the most significant transfer mechanism and a mechanical bond failure occurs when the concrete crushes in front of the lugs. However, it has been suggested that the mechanical bond behaviour of FRP materials will differ from that of steel. ${ }^{9}$ For example, the transverse rigidity of a braided FRP rod is approximately $20 \%$ of that of concrete and hence the FRP rod is likely to slip without causing any local crushing of the concrete. For a rod with an outer winding fibre, the breaking of the winding fibre often leads to a subsequent bond failure. Hence, it is suggested that a failure due to mechanical interlock is initiated by a failure within the FRP material rather than as a result of the crushing of concrete. ${ }^{10}$ However, it is possible that, in some cases, the concrete strength does affect the bond strength and the role of mechanical interlock in the bond behaviour of an FRP/concrete specimen remains a subject of debate.

Chemical adhesion. Adhesion is the chemical bond which is created at the interface between the 
reinforcement and the concrete. With increasing displacement, the adhesive bond strength component is lost.

The findings of ACI Committee $408^{11}$ suggest that, for steel, the bond strength due to adhesion is between 0.48 and $1.03 \mathrm{MPa}$. However, these values include a large factor of safety. In contrast, it is argued there is virtually no adhesion between an FRP rod and concrete. ${ }^{9}$ Work by Treece and Jirsa ${ }^{12}$ also suggests that the adhesion between epoxy-coated reinforcing bars and concrete is minimal.

Nevertheless, the resins used in FRP do take up some moisture so it is likely that there will be some, albeit little, adhesion in FRP/concrete systems. Work by Mal$\operatorname{var}^{13}$ supports this assertion and he found that the adhesion of vinylester or polyester glass-fibre-reinforced (GFRP) rods was in the region of $0 \cdot 7-2 \cdot 1 \mathrm{MPa}$ (approximately twice the ACI values for steel quoted earlier).

Friction. As with mechanical interlock, the frictional bond will be very dependent on the surface characteristics of a rod. Even for steel reinforcement, the frictional resistance can range between 0.41 and $10 \mathrm{MPa}^{11}$

For braided FRP rods it is felt that friction will be the most important bond mechanism, and that the bond resistance of the rod will be the result of the friction generated by the material as the rod fries to squeeze in between the original concrete deformations. ${ }^{9}$ Hence, the coefficient of friction at the tendon-concrete interface, the transverse elastic modulus of the rod and the Poisson's ratio of the FRP are all likely to be influential in determining the frictional bond capacity. ${ }^{14}$

\section{Bond in the transfer zone}

The bond behaviour of FRP rods in the transfer zone is expected to be dominated both by the large Poisson's ratio of the FRPs and the high axial strain capacity of the FRP materials. ${ }^{15}$ Adhesion is unlikely to be a significant factor, since adhesion can only occur prior to slip taking place. ${ }^{16}$

Determination of the Poisson's ratio of FRP rods has proved to be problematic and indeed the Poisson's ratio of FiBRA has been quoted to be as high as 0.52-0.64 (although these results were qualified). ${ }^{1}$ This high value may reflect the response of the braided construction, as well as the direct material properties. The Poisson's ratio for Technora is expected to be around $0 \cdot 35^{7}$ whereas the ratio for steel is approximately $0 \cdot 3$.

If the Poisson's ratio effects are dominant, the surface deformations will have little influence on the bond. Nanni et al. ${ }^{10}$ cite a Japanese study by Khin et al. where the transfer lengths of twelve types of FRP rods were found to be similar and the surface deformations and fibre type had a minimal influence on the bond behaviour.

An additional repercussion of a large Poisson's ratio is the possibility of the concrete splitting during deten- sioning owing to high tensile stresses generated in the concrete as a result of the expansion of the tendon. Work by others has investigated ways of mitigating the possibility of this type of failure. ${ }^{14,17}$

\section{Additional factors which influence bond}

There are several additional factors which must be considered when evaluating the bond characteristics of FRP tendons. In particular, the influence of temperature variations on the bond behaviour is of importance since the transverse coefficient of thermal expansion (CTE) of FRP tends to be much higher than the longitudinal CTE. Hence the possibility of cracking of the concrete due to the transverse thermal expansion of an FRP rod should be considered. Possible changes in the behaviour due to exposure to the environment, time, creep, cyclic loading and fatigue also should be taken into account.

\section{Theoretical analysis of bond stress distribution}

The majority of the proposed analytical solutions for the stresses in the transfer zone consider a thick-walled elastic analysis where a smaller cylinder (the tendon) is surrounded by a larger-diameter outer cylinder (the concrete). ${ }^{16,18,19}$ An alternative to a thick-walled analysis is to incorporate an assumed bond stress distribution into the basic equations of longitudinal equilibrium and compatibility.

Consider a reinforced concrete element of length $\mathrm{d} x$ with a tendon located at its centroid (Fig. 2). A convenient origin for the coordinate $x$ will be defined later. By considering the equilibrium and compatibility equations for the system, the following relationship between the slip $s_{x}$ at a point $x$ and the shear stress $\tau$ at the tendon-concrete interface can be obtained (for further details see Lees $^{20}$ ):

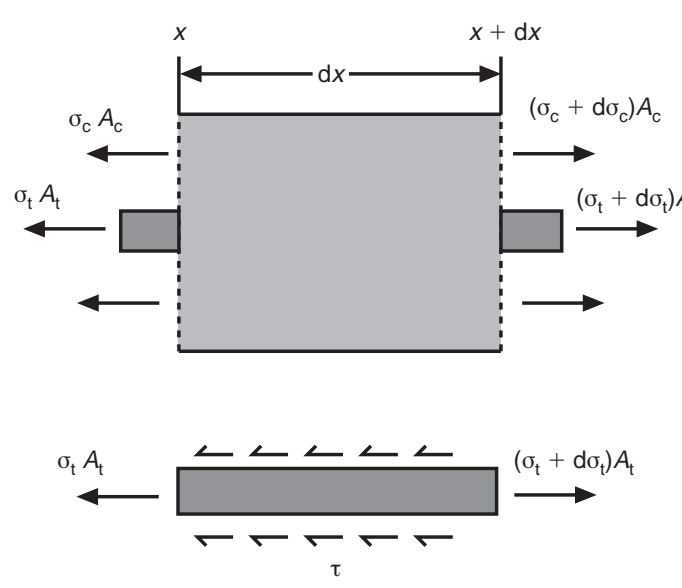

Fig. 2. Stresses in an element 


$$
\frac{\mathrm{d}^{2} s_{x}}{\mathrm{~d} x^{2}}=K \tau
$$

where

$$
K=\frac{4(1+m \rho)}{E_{\mathrm{t}} \phi}
$$

and $m=E_{\mathrm{t}} / E_{\mathrm{c}}$ and $\rho=A_{\mathrm{t}} / A_{\mathrm{c}}$.

Equation (1) is the governing differential equation, but its solution depends on the boundary conditions and also the form assumed for the bond stress-slip relationship.

The boundary conditions are the same for all the cases that will be considered. Prior to detensioning, the force in the tendon $T$ is equal to the initial prestress force $P_{0}$ (Fig. 3). During detensioning, force is transferred from the tendon to the concrete. Provided that the length of the beam is greater than twice the necessary transfer length, then at some position a distance $L_{\mathrm{t}}$ away from the free face of the concrete, the slip $s_{x}$ and the rate of change of slip $\mathrm{d} s_{x} / \mathrm{d} x$ must both be zero. If it is assumed that loss of prestress is negligible then the tensile force in the tendon at this point is equal to the initial prestress force $P_{0}$, whereas at the free end of the beam, the force in the tendon is $P_{\mathrm{d}}$. The difference between these forces, $F=P_{0}-P_{\mathrm{d}}$, is the force that has been transmitted to the concrete. Although the point at which $s_{x}$ and $\mathrm{d} s_{x} / \mathrm{d} x$ are zero is a convenient point from which to measure the value of $x$, this position will move as the force at the end of the tendon, $P_{\mathrm{d}}$, varies. The slip at the face of the concrete will be denoted $s_{d}$.

Three forms of the variation of shear stress with slip can be considered. The shear stress can be assumed to be constant over the region where slipping is taking place, it may be assumed to vary linearly or it may vary non-linearly.

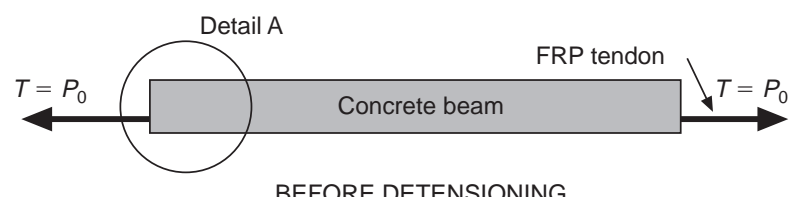

BEFORE DETENSIONING

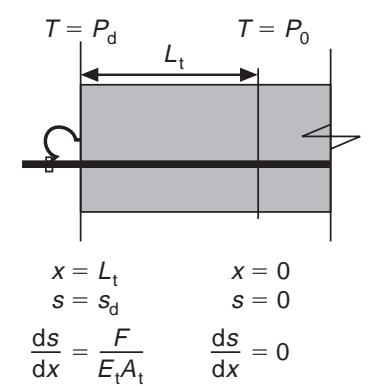

DETAIL A-AFTER DETENSIONING

Fig. 3. Tendon pull-in at prestress release

\section{Constant shear stress}

The bond stress $\tau$ can be taken to have a constant value $b_{1}$ whenever slipping is taking place; hence the differential equation becomes

$$
\frac{\mathrm{d}^{2} s_{x}}{\mathrm{~d} x^{2}}-K b_{1}=0
$$

The solution of this (subject to the boundary conditions detailed above) is given by

$$
s_{x}=\frac{F}{2 L_{\mathrm{t}} A_{\mathrm{t}} E_{\mathrm{t}}} x^{2}
$$

Thus, if the tendon pull-in at the end of the specimen and the tendon force transferred to the concrete are known, then from equation (4) the slip at any point $x$ along the length of the specimen can be calculated. With a knowledge of the form of $\tau$, the change in force in both the tendon and the concrete throughout the transfer zone can also be determined.

\section{Linear shear stress variation}

A slightly more complex relationship between the shear stress and the slip that can be assumed is a linear relationship, so that $\tau=b_{2} s_{x}$. This then leads to

$$
\frac{\mathrm{d}^{2} s_{x}}{\mathrm{~d} x^{2}}-K b_{2} s_{x}=0
$$

which can be solved by assuming a solution of the form

$$
s_{x}=D_{1} \mathrm{e}^{\sqrt{K b_{2}}(x)}+D_{2} \mathrm{e}^{-\sqrt{K b_{2}}(x)}
$$

However, with this form of solution, it is not possible to satisfy the boundary conditions, $s_{x}=0$ and $\mathrm{d} s_{x} /$ $\mathrm{d} x=0$. Nevertheless, it is possible to overcome this limitation by subdividing the variation of the bond stress in the transfer length of the beam into two distinct portions, a frictional section $\left(\tau=b_{1}\right)$ and an elastic section $\left(\tau=b_{2} s\right){ }^{21}$

A linear shear stress variation can also be used where the slip is taking place throughout the length of the specimen (which is often the case in short pull-out specimens). However, in the current work it will not be considered further.

\section{Non-linear shear stress variation}

The most general form of solution is found when the shear stress is assumed to vary non-linearly with slip, so that $\tau=b_{3} s_{x}^{N}$. The differential equation becomes

$$
\frac{\mathrm{d}^{2} s_{x}}{\mathrm{~d} x^{2}}-K b_{3} s_{x}^{N}=0
$$

the solution of which is

$$
s_{x}=\left[\frac{K b_{3}(1-N)^{2}}{2(N+1)}\right]^{1 /(1-N)} x^{2 /(1-N)}
$$


from which

$$
s_{\mathrm{d}}=\left[\frac{(1+N) \phi F^{2}}{8(1+m \rho) b_{3} E_{\mathrm{t}} A_{\mathrm{t}}^{2}}\right]^{1 /(1+N)}
$$

This solution is only valid for $N<1$, since if $N=1$, $L_{\mathrm{t}}$ becomes infinite and if $N>1, L_{\mathrm{t}}$ becomes negative.

\section{Step-by-step release (SSR) method}

Bruggeling $^{22}$ proposed a practical method of determining the form of the bond stress relationship. He assumed a non-linear relationship (with a variable $C$ in place of $b_{3}$ used here), and proposed that the constants $b_{3}$ and $N$ could be determined by measuring the drawin of the prestressed tendon at eight stages during the release of the force. Equation (9) can then be used to derive

$$
\frac{s_{\mathrm{d} 1}}{s_{\mathrm{d} 2}}=\left(\frac{F_{1}^{2}}{F_{2}^{2}}\right)^{1 /(1+N)}
$$

where the subscripts 1 and 2 relate to different load levels. $N$ can be determined from this relationship, and $b_{3}$ found by substituting the results back into equation (9).

Bruggeling $^{23}$ also proposed that the coefficient $b_{3}$ could be adjusted $\left(b_{3 \mathrm{adj}}\right)$ to take into account possible discrepancies due to differences in the concrete strength.

\section{Modified step-by-step release method}

The form of equation (9) suggests an alternative method of determining $b_{3}$ and $N$. By taking logarithms of both sides of this equation, a linear relationship can be found between $\ln \left(s_{\mathrm{d}}\right)$ and $\ln \left(F / A_{\mathrm{t}}\right)$ :

$$
\begin{aligned}
\ln \left(s_{\mathrm{d}}\right)= & \frac{2}{1+N} \ln \left(\frac{F}{A_{\mathrm{t}}}\right)+\frac{1}{1+N} \ln \left[\frac{(1+N) \phi}{8 E_{\mathrm{t}}(1+m \rho)}\right] \\
& -\frac{1}{1+N} \ln \left(b_{3}\right)
\end{aligned}
$$

By performing a linear regression analysis, experimental data can be fitted to equation (11), and the constants $b_{3}$ and $N$ determined.

\section{Additional forms}

Other solution forms are possible. In particular, many distributions have been proposed to describe the bond shear stress versus slip relationship when a tendon is pulled out of a block of concrete. Although the tendon pull-in behaviour is not necessarily the same as the tendon pull-out behaviour (in particular, the sense of the Poisson's ratio effects will reverse), it is possible that such forms are also applicable to the bond stress distribution in the transfer zone.

For example, the Comité Euro-International du Béton (CEB) Model Code ${ }^{24}$ equations were developed, originally for steel, to describe both the ascending and the descending branches of the bond-slip relationship. For FRP rods, the bond mechanisms are unlikely to be the same as those on which the CEB model is based. Nevertheless, there exists a body of experimental work which suggests that the CEB model adequately describes the bond-slip behaviour of FRP bars. ${ }^{25-27}$ Other forms for the entire bond stress-slip curve for FRP materials have also been proposed ${ }^{28,29}$ (and also Malvar, ${ }^{13}$ who included the effect of confinement pressure).

\section{Experimental investigation}

The transfer zone of $100 \times 200 \times 2800 \mathrm{~mm}$ concrete beams was investigated (Fig. 4). The beams prestressed with braided AFRP rods had three tendons $3.7 \mathrm{~mm}$ in diameter (the area of a single tendon was $11 \mathrm{~mm}^{2}$ with an assured tensile load of $15 \cdot 7 \mathrm{kN}$ ), whereas the beams with spiral-wound AFRP rods had only two tendons $4 \mathrm{~mm}$ in diameter (each with an area of $12.6 \mathrm{~mm}^{2}$ and an assured load of $22 \cdot 7 \mathrm{kN}$ ).

These beams were cast as part of a programme to study the response of beams with partially bonded pretensioning tendons, the full details of which are given elsewhere. $^{20}$ Two types of intermittent bond were used (IB1 and IB2), and also tendons with an adhesive coating $(\mathrm{AB})$. In the intermittently bonded beams, discrete lengths of the tendon were alternately bonded and debonded from the concrete. However, in all cases, the tendons were provided with a fully bonded region at each end, $400 \mathrm{~mm}$ long, so that the partial bonding in the centre of the beam was not expected to affect the results given here.

\section{Experimental procedure}

A tensioning system based on the use of expansive cement couplers was used. ${ }^{30}$ In this system, each end of an AFRP tendon was coupled to a piece of prestress wire and the steel/AFRP/steel specimen was then stressed by gripping the steel prestress wire using conventional collets and wedges. Further details of the coupler system can be found elsewhere. ${ }^{31}$
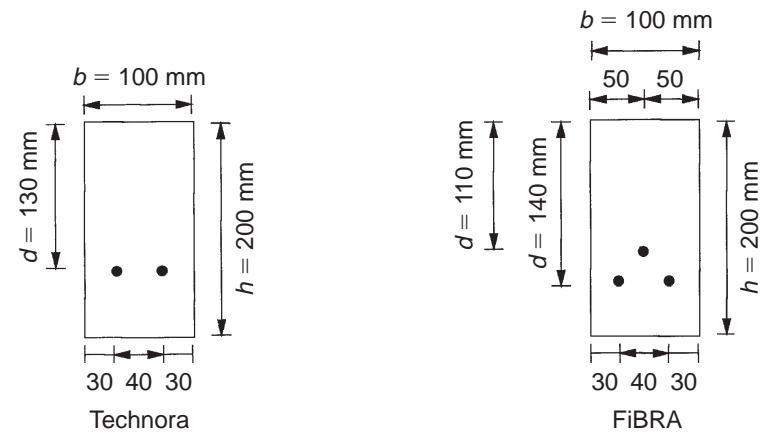

Fig. 4. Beam cross-sections 
Each tendon was tensioned individually to about $0.70 P_{\text {ult }}$, where $P_{\text {ult }}$ is the manufacturer's assured load for the tendon. The force in the tendon was monitored using strain gauges attached to the steel prestress wire and load cells which were inserted at the live end of the tendon. Immediately after tensioning, the pretensioned beams and the concrete control specimens were cast. By this time, the stress level in the tendons had dropped to about $65 \%$ of the manufacturers' assured loads, primarily as a result of short-term relaxation associated with the AFRP materials. This seemed to be a practical level of prestressing and, in view of the timescale of the experiments, long-term stress rupture would not be an issue at these levels of prestressing. ${ }^{32}$

Rapid-hardening Portland cement was used to obtain a high strength at an early age and the concrete cube strength was of the order of $60 \mathrm{MPa}$ at 7 days. Because of the low water-cement ratio $(0 \cdot 37)$, a superplasticizer was added to the mix to improve workability. The coarse aggregate was a $10 \mathrm{~mm}$ glacial pit gravel, and the fine aggregate a sharp sand. Details of the mix proportions have been given by Lees. ${ }^{20}$

The concrete was left to harden and the beams were typically detensioned five days after casting. Strain hoops with a gauge length of between 35 and $37 \mathrm{~mm}$ were attached to the beams to monitor the pull-in of the tendons during detensioning (see Fig. 3). The testing of concrete control specimens indicated that the average concrete cube strength at transfer was around $55 \mathrm{MPa}$ and the average modulus of elasticity $E_{\mathrm{c}}$ was $22000 \mathrm{MPa}$.

\section{Experimental results}

A summary of results for the pull-in of the tendon as a result of detensioning can be found in Table 2 (the values in the table are the measured pull-in minus the elastic shortening of the tendon over the base length of the strain hoop). The draw-in was measured at both ends of a tendon and in Table 2 the live end is referred to as ' $a$ ' and the dead end as ' $b$ '. The beam nomenclature corresponds to the flexural tests described elsewhere. ${ }^{8}$

During detensioning, the force in the tendon at the free end of the beam, $P_{\mathrm{d}}$, varied from $P_{0}$ to zero. The experimental data were analysed to determine the region of stress over which the readings were smooth. Hence, in Table 2, the tendon force $P_{\mathrm{d}}$ which corresponds to the stated value of tendon pull-in $s_{\mathrm{d}}$ has been included and the bond stress and transfer lengths have been calculated accordingly.

Table 2. Pull-in at prestress release for beam tests-The transfer length and shear stress are calculated assuming a constant bond stress distribution

\begin{tabular}{|c|c|c|c|c|c|c|c|}
\hline Material & Test/tendon* & Length: mm & $P_{0}: \mathrm{kN}$ & $P_{\mathrm{d}}: \mathrm{kN}$ & Pull-in $s_{\mathrm{d}}: \mathrm{mm}$ & $L_{\mathrm{t}}: \mathrm{mm}$ & $\tau_{\mathrm{t}}: \mathrm{MPa}$ \\
\hline FiBRA & $\mathrm{FIB} 1 / 1 \mathrm{a}$ & 2800 & $9 \cdot 6$ & $0 \cdot 1$ & 0.74 & 118 & $7 \cdot 0$ \\
\hline FiBRA & $\mathrm{FIB} 1 / 2 \mathrm{a}$ & 2800 & $9 \cdot 9$ & $0 \cdot 1$ & $0 \cdot 79$ & 122 & $6 \cdot 9$ \\
\hline FiBRA & $\mathrm{FIB} 1 / 3 \mathrm{a}$ & 2800 & $9 \cdot 8$ & $0 \cdot 8$ & $0 \cdot 56$ & 94 & $8 \cdot 2$ \\
\hline FiBRA & FIB $1 / 1 b$ & 2800 & $9 \cdot 2$ & $0 \cdot 1$ & $0 \cdot 71$ & 118 & $6 \cdot 6$ \\
\hline FiBRA & $\mathrm{FIB} 1 / 2 \mathrm{~b}$ & 2800 & $9 \cdot 9$ & $0 \cdot 5$ & 0.92 & 148 & $5 \cdot 5$ \\
\hline FiBRA & $\mathrm{FIB} 1 / 3 \mathrm{~b}$ & 2800 & $9 \cdot 8$ & $0 \cdot 5$ & 0.69 & 112 & $7 \cdot 1$ \\
\hline FiBRA & $\mathrm{FIB} 2 / 1 \mathrm{a}$ & 2800 & $10 \cdot 0$ & $0 \cdot 7$ & $0 \cdot 72$ & 117 & $6 \cdot 8$ \\
\hline FiBRA & $\mathrm{FIB} 2 / 2 \mathrm{a}$ & 2800 & $10 \cdot 4$ & $0 \cdot 3$ & $0 \cdot 81$ & 121 & $7 \cdot 2$ \\
\hline FiBRA & $\mathrm{FIB} 2 / 3 \mathrm{a}$ & 2800 & $10 \cdot 5$ & $1 \cdot 2$ & $0 \cdot 70$ & 114 & $7 \cdot 0$ \\
\hline FiBRA & $\mathrm{FIB} 2 / 1 \mathrm{~b}$ & 2800 & $9 \cdot 6$ & $0 \cdot 6$ & $0 \cdot 50$ & 84 & $9 \cdot 2$ \\
\hline FiBRA & $\mathrm{FIB} 2 / 2 \mathrm{~b}$ & 2800 & $10 \cdot 1$ & $0 \cdot 1$ & $0 \cdot 69$ & 104 & $8 \cdot 3$ \\
\hline FiBRA & $\mathrm{FIB} 2 / 3 \mathrm{~b}$ & 2800 & $10 \cdot 4$ & $0 \cdot 8$ & $0 \cdot 72$ & 113 & $7 \cdot 3$ \\
\hline FiBRA & $\mathrm{FAB} / 1 \mathrm{a}$ & 2800 & $10 \cdot 1$ & $0 \cdot 9$ & $0 \cdot 65$ & 107 & $7 \cdot 4$ \\
\hline FiBRA & $\mathrm{FAB} / 2 \mathrm{a}$ & 2800 & $10 \cdot 1$ & $0 \cdot 2$ & $0 \cdot 76$ & 116 & $7 \cdot 4$ \\
\hline FiBRA & $\mathrm{FAB} / 3 \mathrm{a}$ & 2800 & $9 \cdot 9$ & $0 \cdot 1$ & 0.53 & 82 & $10 \cdot 3$ \\
\hline FiBRA & $\mathrm{FAB} / 1 \mathrm{~b}$ & 2800 & $9 \cdot 9$ & $0 \cdot 1$ & 0.58 & 89 & $9 \cdot 4$ \\
\hline FiBRA & $\mathrm{FAB} / 2 \mathrm{~b}$ & 2800 & $10 \cdot 4$ & $0 \cdot 3$ & 0.78 & 117 & $7 \cdot 5$ \\
\hline FiBRA & $\mathrm{FAB} / 3 \mathrm{~b}$ & 2800 & $10 \cdot 1$ & $0 \cdot 1$ & $0 \cdot 64$ & 97 & 8.9 \\
\hline Technora & TIB1/1a & 2800 & $14 \cdot 5$ & $0 \cdot 4$ & $0 \cdot 47$ & 45 & $24 \cdot 8$ \\
\hline Technora & $\mathrm{TIB} 1 / 2 \mathrm{a}$ & 2800 & $14 \cdot 7$ & $0 \cdot 9$ & $0 \cdot 96$ & 94 & $11 \cdot 6$ \\
\hline Technora & TIB1/1b & 2800 & $14 \cdot 3$ & $1 \cdot 0$ & 0.53 & 54 & $19 \cdot 6$ \\
\hline Technora & $\mathrm{TIB} 1 / 2 \mathrm{~b}$ & 2800 & $15 \cdot 0$ & $1 \cdot 0$ & $0 \cdot 80$ & 78 & $14 \cdot 4$ \\
\hline Technora & TIB2/1a & 2800 & $14 \cdot 8$ & $0 \cdot 6$ & 0.58 & 55 & $20 \cdot 4$ \\
\hline Technora & $\mathrm{TIB} 2 / 2 \mathrm{a}$ & 2800 & $14 \cdot 5$ & $0 \cdot 8$ & $0 \cdot 60$ & 59 & $18 \cdot 4$ \\
\hline Technora & TIB $2 / 1 b$ & 2800 & $14 \cdot 7$ & $1 \cdot 2$ & 0.53 & 53 & $20 \cdot 2$ \\
\hline Technora & $\mathrm{TIB} 2 / 2 \mathrm{~b}$ & 2800 & $14 \cdot 5$ & $0 \cdot 4$ & $0 \cdot 6$ & 58 & $19 \cdot 4$ \\
\hline Technora & $\mathrm{TAB} / 1 \mathrm{a}$ & 2800 & $14 \cdot 5$ & $1 \cdot 4$ & $0 \cdot 57$ & 59 & $17 \cdot 7$ \\
\hline Technora & $\mathrm{TAB} / 2 \mathrm{a}$ & 2800 & $14 \cdot 6$ & $1 \cdot 2$ & $0 \cdot 60$ & 61 & $17 \cdot 6$ \\
\hline Technora & $\mathrm{TAB} / 1 \mathrm{~b}$ & 2800 & $14 \cdot 5$ & $0 \cdot 2$ & $0 \cdot 58$ & 55 & $20 \cdot 7$ \\
\hline Technora & $\mathrm{TAB} / 2 \mathrm{~b}$ & 2800 & $14 \cdot 6$ & $0 \cdot 1$ & $0 \cdot 50$ & 47 & $24 \cdot 7$ \\
\hline
\end{tabular}

* Each beam is identified by a series of letters and, in some cases, a number. The first letter indicates the type of tendon material and the next set of characters identifies the tendon bond condition, as follows: T, $4 \mathrm{~mm}$ deformed Technora rod; F, $3 \cdot 7 \mathrm{~mm}$ braided FiBRA; IB1, intermittently bonded series 1; IB2, intermittently bonded series 2 ; AB, adhesive bonded. 
The transfer lengths $L_{\mathrm{t}}$ and bond stresses $\tau_{\mathrm{t}}$ corresponding to the experimental pull-in data were then calculated using two different methods. In the first method, a constant bond stress distribution was assumed. In the second method, the assumed bond stress distribution was of the form suggested by Bruggeling.

Constant bond stress distribution. If a constant bond stress is assumed to act along the length of the transfer zone, the tension in the tendon will increase linearly throughout the transfer length. The values of the transfer length $L_{\mathrm{t}}$ and the bond stress $\tau_{\mathrm{t}}$ through this region can be determined accordingly (see Table 2).

Varying bond stress distribution. The original SSR method $^{23}$ was modified in the current work since, although the pull-in had been monitored fairly continuously during detensioning, the readings did not directly correspond to the levels specified in the SSR method.

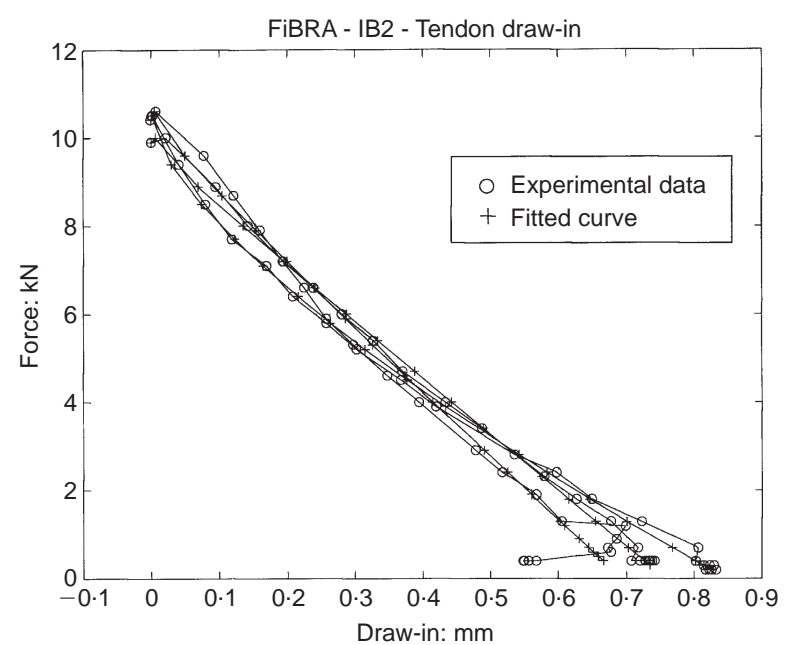

The experimental coefficients were determined by carrying out a linear regression of the data using equation (11). From the parameters of the fitted curve (Fig. 5), the values of $N$ and $b_{3}$ were determined. This curve-fitting process can produce values for $N>1$ which, as noted in an earlier section, are invalid. However, for completeness, these values have been included here. Later, when typical values are taken for the two materials, the results with $N>1$ will be discarded.

To mitigate the effect of the experimental influences noted at high and low stress levels which did not conform to the general trend of results, the curve fitting was performed only on data which lay between $0.82 P_{0}$ and $0.07 P_{0}$. These values correspond to the upper and lower limits suggested in the SSR method.

The coefficients $N$ and $b_{3}$ shown in Table 3 were determined from the data corresponding to the beam tests IB1, IB2 and AB and have been plotted in Fig. 6. There is considerable scatter in the results, particularly

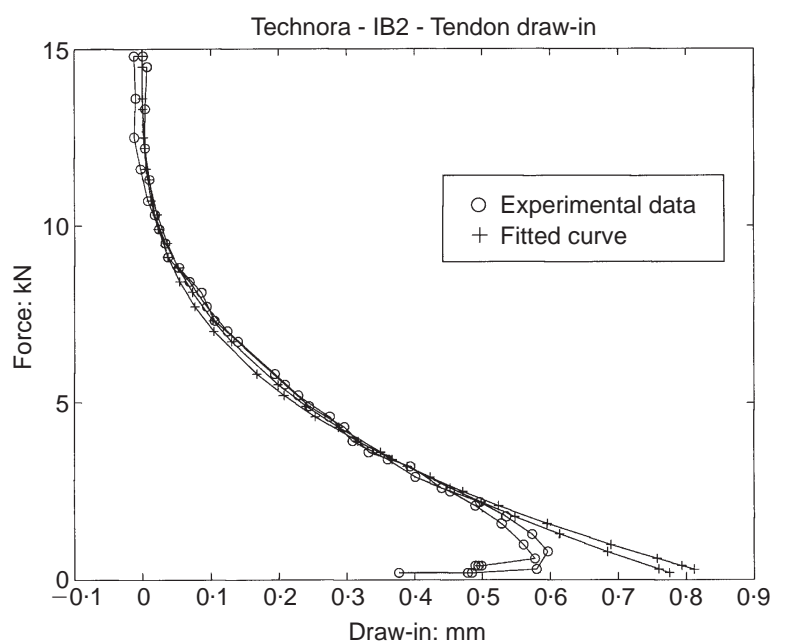

Fig. 5. Curve fitting of tendon draw-in data

Table 3. $N$ and $b_{3}$ values based on the curve fitting of the experimental data

\begin{tabular}{|c|c|c|c|c|c|c|}
\hline \multirow[t]{2}{*}{ Material } & \multirow[t]{2}{*}{ Test/tendon } & \multicolumn{2}{|c|}{ Dead end } & \multicolumn{2}{|c|}{ Live end } & \multirow[t]{2}{*}{$f_{\mathrm{cu}}: \mathrm{MPa}$} \\
\hline & & $N$ & $b_{3}$ & $N$ & $b_{3}$ & \\
\hline FiBRA & IB1/1 & $1 \cdot 04$ & $20 \cdot 41$ & $0 \cdot 80$ & $16 \cdot 91$ & 56 \\
\hline FiBRA & $\mathrm{IB} 1 / 2$ & 0.66 & $13 \cdot 27$ & $1 \cdot 44$ & $15 \cdot 60$ & 56 \\
\hline FiBRA & IB $1 / 3$ & 0.96 & $28 \cdot 39$ & $1 \cdot 17$ & $26 \cdot 26$ & 56 \\
\hline FiBRA & IB2/1 & 0.91 & $17 \cdot 72$ & 0.55 & $21 \cdot 41$ & $56 \cdot 3$ \\
\hline FiBRA & $\mathrm{IB} 2 / 2$ & $0 \cdot 40$ & $10 \cdot 59$ & 0.47 & $16 \cdot 23$ & $56 \cdot 3$ \\
\hline FiBRA & IB $2 / 3$ & $0 \cdot 86$ & $22 \cdot 49$ & 0.45 & $12 \cdot 25$ & $56 \cdot 3$ \\
\hline FiBRA & $\mathrm{AB} / 1$ & 0.97 & $28 \cdot 07$ & 0.63 & $23 \cdot 01$ & 58 \\
\hline FiBRA & $\mathrm{AB} / 2$ & $1 \cdot 23$ & $26 \cdot 45$ & 0.47 & $12 \cdot 91$ & 58 \\
\hline FiBRA & $\mathrm{AB} / 3$ & $1 \cdot 61$ & $78 \cdot 03$ & $0 \cdot 83$ & $25 \cdot 95$ & 58 \\
\hline Technora & IB1/1 & $-0 \cdot 33$ & $10 \cdot 21$ & $-0 \cdot 23$ & $12 \cdot 27$ & 56 \\
\hline Technora & IB1/2 & $0 \cdot 02$ & $12 \cdot 40$ & 0.02 & $14 \cdot 65$ & 56 \\
\hline Technora & IB2 / 1 & $-0 \cdot 39$ & $8 \cdot 49$ & $-0 \cdot 41$ & $8 \cdot 51$ & $56 \cdot 3$ \\
\hline Technora & IB $2 / 2$ & $-0 \cdot 32$ & $9 \cdot 73$ & $-0 \cdot 51$ & $6 \cdot 45$ & $56 \cdot 3$ \\
\hline Technora & $\mathrm{AB} / 1$ & $0 \cdot 23$ & $28 \cdot 75$ & $-0 \cdot 28$ & $11 \cdot 23$ & 58 \\
\hline Technora & $\mathrm{AB} / 2$ & $-0 \cdot 28$ & $10 \cdot 61$ & $-0 \cdot 46$ & $7 \cdot 90$ & 58 \\
\hline
\end{tabular}




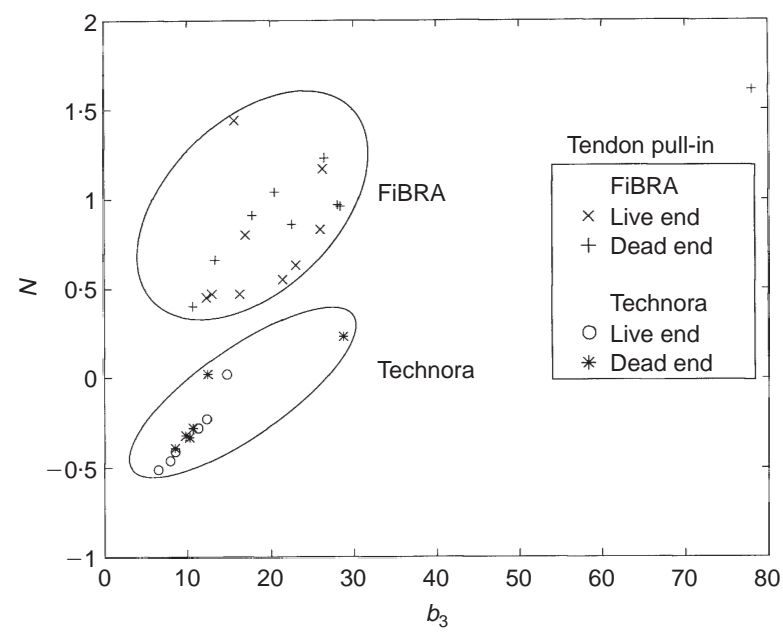

Fig. 6. Calculated $\mathrm{N}$ and $b_{3}$ coefficients (see also Table 3)

for the FiBRA. One possible explanation is that, as a result of the braiding process, the FiBRA is characterized by a central epoxy core. As the Poisson's ratio is somewhat dependent on the size of this central epoxy core it is possible that the Poisson's ratio will vary between tendons.

\section{Experimental limitations}

The measured pull-in results were taken to be representative of the pull-in of the composite FRP rod. The possibility that the pull-in of the outer, resin-rich layer of the FRP tendon might differ from the displacement of the inner layers was not considered in the present work.

Since FRPs are susceptible to damage, great care was taken to ensure that the tendons did not catch on the stop-ends during the stressing of the FRP tendons. Oversized holes were drilled in the stop-ends and ample lubrication in the form of petroleum jelly was provided. Although attention was paid to ensuring that the length of tendon cast into the beam was free of any such lubrication, it is possible that the tendons were not entirely clean.

\section{Discussion}

When a constant bond stress distribution is assumed, no insight can be gained into the possible variation of the bond shear stress distribution along the length of the tendon. However, this type of distribution is simple to apply and gives an indication of the magnitude of the bond stresses that are generated with a particular type of rod. From the results in Table 2, the average transfer bond stress for FiBRA was $7 \cdot 7 \mathrm{MPa}$. For the Technora, the average stress was $17 \cdot 1 \mathrm{MPa}$. On the basis of these calculated mean transfer stresses, the length required to transfer $0.65 P_{\text {ult }}$ would be $114 \mathrm{~mm}$ for the FiBRA (approximately $30 \phi$ ) and $69 \mathrm{~mm}$ for the Technora (approximately $17 \phi$ ).
The use of a non-linear bond stress formulation provides much more information about how the bond stresses might vary along the length of the tendon. Referring to Fig. 6, representative experimental values of $N$ and $b_{3}$ for FiBRA and Technora could be taken to be $N=0 \cdot 8, b_{3}=20$ and $N=-0 \cdot 35, b_{3}=10$, respectively. Using these values of $N$ and $b_{3}$, a plot of the shear stress at the face of the specimen versus draw-in for FiBRA, Technora and steel is shown in Fig. 7. Although the draw-in of a steel wire was not measured in the current work, Bruggeling ${ }^{22}$ suggests that for a single strand of steel prestress wire $N=0.27$ and $b_{3}=6 \cdot 6$. For all materials, the initial prestress levels were assumed to be $0.65 P_{\text {ult }}$.

The shapes of the three curves are very different, which suggests that the bond behaviour is also very different. The bond shear stress in Technora decreases sharply as the tendon pull-in increases, whereas the bond shear stresses in both the FiBRA and the steel specimens increase with increasing pull-in. In addition, the shear stress in the FiBRA rises almost linearly, whereas the slope of the predicted curve for steel decreases as the tendon draw-in increases. These behavioural trends are almost certainly due to the different surface profiles of the rods.

The transfer lengths and the variation in the stress distribution along the length of the transfer zone can also be calculated using the proposed formulation. For a typical case where the tendons are stressed to $65 \%$ of their ultimate stress, the corresponding bond shear stress distribution along the length of the transfer zone can be found in Fig. 8 .

The shapes of the FiBRA and Technora bond shear curves are convex, whereas the steel curve is concave. The shapes of the predicted FiBRA and steel stress distributions are consistent with the results of a study by Nanni et al. ${ }^{15}$ These authors also noted that after detensioning, a plot of the change in tendon strain (and hence the bond shear stress) with respect to distance was convex for FiBRA and concave for steel.

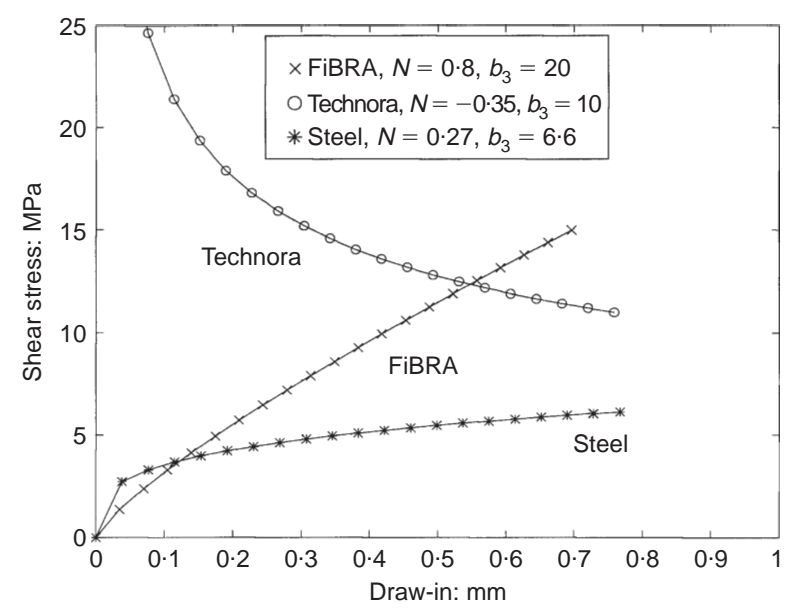

Fig. 7. Bond shear stress versus tendon draw-in

Magazine of Concrete Research, 1999, 51, No. 4 


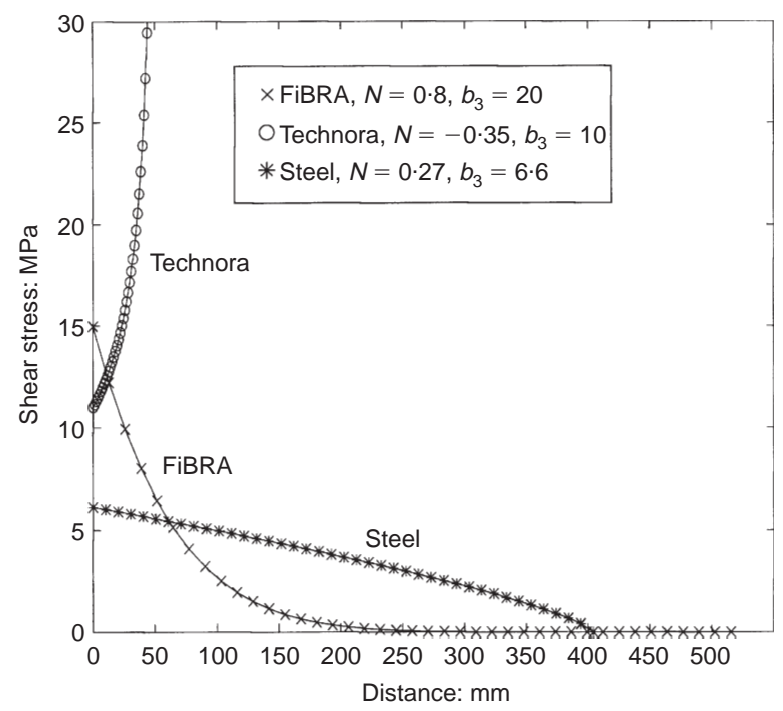

Fig. 8. Bond shear stress versus distance from the beam end

The transfer length for Technora, $52 \mathrm{~mm}$, is much shorter than that for FiBRA, $515 \mathrm{~mm}$, and that for steel, $405 \mathrm{~mm}$. In Fig. 9, the variation of the tendon stress along the length of the transfer zone is shown. In contrast to the steel and the Technora, the stress distribution in the FiBRA is characterized by an almost asymptotic region where the stress approaches the initial prestress level. Hence, although the transfer length of FiBRA is quite long, the bond stresses decrease rapidly and a transfer length of less than $200 \mathrm{~mm}$ is required to transfer $95 \%$ of the force. The stress in the Technora rises steeply and it appears that the tendon is 'locked' at the end of its transmission length, presumably by some sort of mechanical interlocking effect.

As stated earlier, the fully bonded anchorage region for both the Technora and the FiBRA beams was only

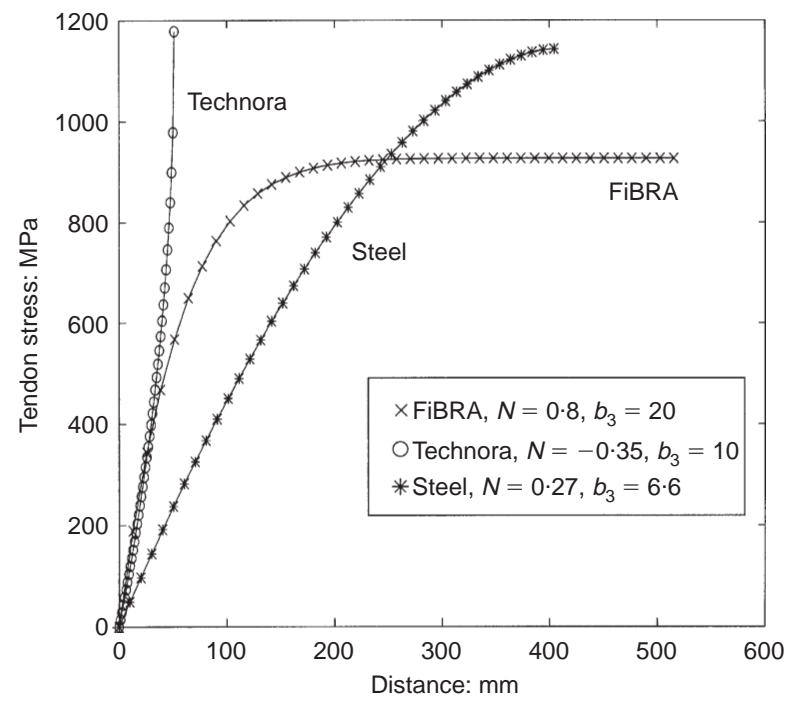

Fig. 9. Tendon stress versus distance from the beam end
$400 \mathrm{~mm}$ (this was the point at which the tendon became partially bonded). Hence, if the transfer length of the FiBRA was greater than $400 \mathrm{~mm}$, it is possible that the pull-in results would include some element of slip in the partially bonded region of the tendon.

\section{Practical implications}

The presence of the outer winding fibre on the Technora seemed to enhance the mechanical-interlocking component of the bond strength. However, if the outer winding fibre were to fail, the release of stress could have negative implications. For the FiBRA it was unfortunately not possible to distinguish between the component of resistance due to the Poisson's ratio effect and that due to mechanical bond.

As noted with the spiral-wound FRP, the bond strengths of FRP rods can be very high. Although this implies shorter transfer lengths, care must be taken that any tensile stresses generated in the surrounding concrete do not result in cracking. An additional repercussion for a member under flexural or shear loading is that, if the concrete cracks in the span, minimal debonding is expected on either side of a crack. As a result, high strains will be induced in the tendon in a localized region. For these linear elastic materials, high strains result in high stresses.

The SSR method proposed by Bruggeling proved to be extremely powerful. The measurement of the tendon force and tendon draw-in during detensioning are straightforward procedures. Yet from these measurements insight into the actual stress distribution throughout the transfer zone can be obtained.

There was a great deal of scatter in the results presented here. This would suggest that a fairly comprehensive test programme would need to be carried out to establish possible variations in bond strengths of an FRP rod. Bruggeling ${ }^{33}$ considered the statistical variation of the results presented in the current work. He concluded that the application of the original SSR method (where readings are taken at set levels of prestress), coupled with an appropriate statistical evaluation, produced consistent results. It is therefore suggested that this method could represent a practical, reliable means of testing for the bond strength of a given reinforcement bar.

\section{Conclusions}

(a) Both the surface profile and the material properties of an FRP tendon can have a significant effect on the bond behaviour of a tendon.

(b) In order to investigate the force distribution in the transfer zone, an assumed bond shear stress versus slip relationship can be incorporated into equations based on the longitudinal equilibrium 
and compatibility of an element in the transfer zone. Typically either a constant, linear or nonlinear relationship between the bond shear stress and slip is assumed.

(c) Although the assumption of a constant bond stress provides a straightforward way of determining the possible length of the transfer zone, no insight is gained into possible variations in the bond stress through the transfer zone. In contrast, when a non-linear bond stress distribution is assumed, the distinctly different nature of the bond behaviour of different materials can be observed.

(d) When a non-linear distribution is assumed, the transfer length of the braided AFRP is longer than that of the steel or the spiral-wound AFRP. However, the transfer bond stresses for the braided AFRP decrease rapidly and the transfer length required to transfer $95 \%$ of the force is less than $40 \%$ of the length required to transfer $100 \%$ of the force. The spiral-wound AFRP is characterized by a very short transfer length. The transfer bond stresses increase rapidly at the end of the transfer zone and it appears that the tendon is 'locked' at the end of its transmission length.

(e) The SSR method offers a novel way of analysing the experimental pull-in data, and some interesting results about the distinctly different natures of the bond behaviour of the three materials FiBRA, Technora and steel were obtained. Further tests are required to extend the results of the current work.

\section{Acknowledgements}

The authors are grateful for the support of Teijin Ltd and Mitsui Construction Co. Kevlar is a trade name of Du Pont, Technora of Teijin and FiBRA of Mitsui. One of the authors (JML) was sponsored by the Natural Sciences and Engineering Research Council of Canada (NSERC) and is appreciative of NSERC's financial assistance.

\section{References}

1. Tanigaki M., OKamoto T., Tamura T., Matsubara S. and NomURA S. Study of braided aramid fiber rods for reinforcing concrete. IABSE, 13th Conference, Helsinki, 1988, 15-20.

2. Nanni A., Okамото T., Tanigaki M. and Osakada S. Tensile properties of braided FRP rods for concrete reinforcement. $\mathrm{Ce}$ ment and Concrete Composites, 1993, 15, No. 3, 121-129.

3. Mera H. and TAKATA T. High performance fibers. In Ullmann's Encyclopedia of Industrial Chemistry, 5th edn. VCH, Weinheim, 1989, vol. A 13.

4. Teijin Ltd. High Tenacity Aramid Fibre-Technora, Teijin Ltd., Tokyo, 1989, Technical Information TIE-05/89.11.

5. TAmURA T. FiBRA. In Fiber-Reinforced-Plastic (FRP) Reinforcement for Concrete Structures: Properties and Applications (ed. A. Nanni). Elsevier, Amsterdam, 1993, pp. 291-303.
6. Kakihara R., Kamiyoshi M., Kumagai S. and Noritake K. A new aramid rod for the reinforcement of prestressed concrete structures. Proceedings of Advanced Composites Materials in Civil Engineering Structures, Las Vegas, 1991, pp. 132-142.

7. Noritake K., Kakihara R., Kumagai S. and Mizutani J. Technora, an aramid FRP rod. In Fiber-Reinforced-Plastic (FRP) Reinforcement for Concrete Structures: Properties and Applications (ed. A. Nanni). Elsevier, Amsterdam, 1993, pp. 267-290.

8. Lees J. M. and Burgoyne C. J. Experimental study of the influence of bond on the flexural behaviour of concrete beams pretensioned with AFRPs. American Concrete Institute Structural Journal, 1995, 95, No. 3.

9. Dolan C. W. and Nanni A. Status of fiber-reinforced plastic reinforcement development and cement based research needs. Advanced Cement Based Materials, 1994, 1, 185-191.

10. NANni A., Bakis C. E. and Boothby T. E. Test methods for FRP-concrete systems subjected to mechanical loads: state of the art review. Journal of Reinforced Plastics and Composites, 1995, 14, No. 6, 524-558.

11. ACI Committee 408. Abstract of: state-of-the-art-report: bond under cyclic loads. American Concrete Institute Materials Journal, 1991, 88, No. 6, 669-673.

12. Treece R. A. and Jirsa J. O. Bond strength of epoxy-coated reinforcing bars. American Concrete Institute Materials Journal, 1989, 86, No. 2, 167-174.

13. Malvar L. J. Tensile and bond properties of GFRP reinforcing bars. American Concrete Institute Materials Journal, 1995, 92, No. 3, 276-285.

14. Nanni A., Tanigaki M. and Hasuo K. Bond anchorage of pretensioned FRP tendon at force release. American Society of Civil Engineers Journal of Structural Engineering, 1992, 118, No. 10, 2837-2854.

15. Nanni A., Utsunomiya T., Yonekura H. and Tanigaki M. Transmission of prestressing force to concrete by bonded fibre reinforced plastic tendons. American Concrete Institute Structural Journal, 1992, 89, No. 3, 335-344.

16. Hognestad E. and JANneY J. R. The ultimate strength of pretensioned prestressed concrete failing in bond. Magazine of Concrete Research, 1954, 6, 11-16.

17. Taerwe L. and Pallemans I. Force transfer of AFRP bars in concrete prisms. Non-Metallic (FRP) Reinforcement for Concrete Structures-Proceedings of the Second International RILEM Symposium (FRPRCS-2) (ed. L. Taerwe). E \& FN Spon, London, 1995, RILEM Proceedings 29, pp. 154-163.

18. Evans R. H. Research and developments in pre-stressing. Proceedings of the Institution of Civil Engineers, 1951, 35-36, No. 4, 231-261.

19. JANNEY J. R. Nature of bond in pre-tensioned prestressed concrete. Journal of the American Concrete Institute, 1954, 50, 717-736.

20. LeEs J. M. Flexure of Concrete Beams Pre-Tensioned with Aramid FRPs. PhD thesis, University of Cambridge, 1997.

21. Guyon Y. Prestressed Concrete I, 4th edn. Contractors Record Ltd, London, 1960.

22. Bruggeling A. S. G. Structural Concrete-Theory and its Application. Balkema, Rotterdam, 1991.

23. Bruggeling A. S. G. Description of the SSR Method for the Experimental Determination of the Actual Transmission Length and Relevant Parameters. CUR, Gouda, The Netherlands, 1995, Technical Report 150502.

24. Comité Euro-International du Béton. CEB-FIP Model Code 1990 - Final Draft. CEB, Lausanne, Bulletin d'Information 203, 1991, chaps 1-3.

25. Cosenza E., Manfredi G. and Realfonzo R. Analytical modelling of bond between FRP reinforcing bars and concrete. NonMetallic (FRP) Reinforcement for Concrete Structures-Proceedings of the Second International RILEM Symposium (FRPRCS-2) (ed. L. Taerwe). E \& FN Spon, London, 1995, RILEM Proceedings 29 , pp. $164-171$. 
26. FAORO M. The influence of stiffness and bond of FRP bars and tendons on the structural behaviour of reinforced concrete members. Advanced Composite Materials in Bridges and Structures2nd International Conference (ed. M. M. El-Badry). Canadian Society for Civil Engineering, Montreal, 1996, pp. 885-892.

27. Alunno Rossetti V., Galeota D. and Giammatteo M. M. Local bond stress-slip relationships of glass fibre reinforced plastic bars embedded in concrete. RILEM Materials and Structures-Research and Testing, 1995, 28, No. 180, 340-344.

28. Cosenza E., Manfredi G. and Realfonzo R. Bond characteristics and anchorage length of FRP rebars. Advanced Composite Materials in Bridges and Structures-2nd International Conference (ed. M. M. El-Badry). Canadian Society for Civil Engineering, Montreal, 1996, pp. 909-916.

29. Rostásy F. S. and Budelmann H. Principles of design of FRP tendons and anchorages for post-tensioned concrete. Fiber-Reinforced-Plastic Reinforcement for Concrete Structures-International Symposium (eds A. Nanni and C. W. Dolan). American Concrete Institute, Detroit, 1993, SP-138, pp. 633-650.

30. Harada T., Idemitsu T., Watanabe A., Khin M. and Soeda K. New FRP tendon anchorage system using highly expansive material for anchoring. Modern Prestressing Techniques and Their Applications, Proceedings, FIP '93 Symposium. Japan Prestressed Concrete Engineering Association, Tokyo, 1993, vol. II, pp. 711-718

31. Lees J. M., Gruffydd-Jones B. and Burgoyne C. J. Expansive cement couplers - a means of pre-tensioning fibre-reinforced plastic tendons. Construction and Building Materials, 1995, 9, No. 6, 413-423.

32. Gerritse A. Aramid-based prestressing tendons. In Alternative Materials for the Reinforcement and Prestressing of Concrete (ed. J. L. Clarke). Blackie Academic \& Professional, London, 1993, pp. 172-201.

33. Bruggeling A. S. G. Controlling transmission of prestress by bond in progress. In Betonbau in Forschung und Praxis, Festschrift zum 60. Geburstag von György Iványi (ed. W. Buschmeyer). Verlag Bau + Technik GmbH, Düsseldorf, 1999.

Discussion contributions on this paper should reach the editor by 31 May 2000 